\title{
Controle químico da ferrugem asiática da soja em função de ponta de pulverização e de volume de calda
}

\author{
Soybean asian rust control influenced by spray volumes and spray nozzles
}

\author{
João Paulo Arantes Rodrigues da Cunha ${ }^{1}$ Elton Fialho dos Reis ${ }^{2}$ \\ Roberto de Oliveira Santos ${ }^{3}$
}

\section{RESUMO}

As pontas de pulverização são um dos componentes mais importantes dos pulverizadores hidráulicos para aplicação de agrotóxicos. O presente trabalho teve como objetivo avaliar o controle químico da ferrugem asiática e a deposição da calda fungicida aplicada na cultura da soja, em função de diferentes volumes de aplicação e de tipos de ponta de pulverização. $O$ ensaio foi conduzido no delineamento em blocos ao acaso, com quatro repetições, em esquema bifatorial $(4 \times 2)+1$ : quatro tipos de ponta de pulverização (jato plano padrão, jato plano de pré-orifício, jato plano de indução de ar e jato plano duplo de indução de ar), dois volumes de aplicação (115 e $160 \mathrm{~L} \mathrm{ha}^{-1}$ ) e um tratamento adicional, que não recebeu fungicida (testemunha). Realizou-se a semeadura direta da cultivar “Emgopa 313” (ciclo tardio), avaliando-se, após a aplicação do fungicida tebuconazole com as diferentes pontas e volumes, a deposição de calda no dossel da cultura, a severidade da ferrugem e a produtividade. Constatou-se que, apesar de o volume de calda de $160 \mathrm{~L} \mathrm{ha}^{-1}$ e de a utilização da ponta de jato plano padrão terem proporcionado maior uniformidade de distribuição da calda fungicida nas plantas, não houve influência do tipo de ponta de pulverização e do volume de aplicação no controle da ferrugem e na produtividade da cultura da soja. O fungicida tebuconazole propiciou bom controle da ferrugem, refletindo na produtividade de grãos, que foi, em média, $41 \%$ superior à obtida na testemunha.

Palavras-chave: tecnologia de aplicação, bicos de pulverização, Glycine max L., Phakopsora pachyrhizi.

\section{ABSTRACT}

The spray nozzles are one of the most important components of pesticide hydraulic sprayers. This study aimed at evaluating the chemical control of the rust and the deposition of fungicide sprayed on soybean concerning different nozzles, and application volumes. A randomized complete-block design with four replications was used, in a factorial model $\left(\begin{array}{l}4 \times 2 \\ x\end{array}\right)+$ 1: four spray nozzles (standard flat fan, pre-orifice flat fan, air induction flat fan and air induction twin flat fan), two spray volumes (115 and 160L ha-1) and the control (non-treated plot). Emgopa 313 soybean (long cycle) were sown. After the application of the fungicide tebuconazole, with the different nozzles and volume rates, the spray deposition in the plant canopy, the rust severity, and the yield were evaluated. The results showed that, despite the fact of the volume rate of $160 \mathrm{~L}$ $h a^{-1}$ and of the use of the standard flat fan nozzles have provided larger fungicide distribution uniformity in the plant canopy, there was not influence of the nozzle type neither of the application volume in the control of the rust as well as in the soybean yield. The fungicide has provided a good control of the rust, increasing the soybean yield, that was, on average, $41 \%$ superior to that obtained in the control.

Key words: application technology, spray nozzles, Glycine max L., Phakopsora pachyrhizi.

\section{INTRODUÇÃO}

O controle químico da ferrugem asiática (Phakopsora pachyrhizi H. Sydow \& Sydow) é uma das principais preocupações dos produtores após o florescimento da soja [Glycine max (L.) Merrill]. No momento em que as plantas atingem o grau máximo de desenvolvimento vegetativo, com total fechamento e grande área foliar, as aplicações necessitam da máxima capacidade de penetração na massa de folhas e cobertura das mesmas, mesmo para a aplicação de

${ }^{1}$ Instituto de Ciências Agrárias, Universidade Federal de Uberlândia, Campus Umuarama, 38400-902, Uberlândia, MG, Brasil. Email: jpcunha@iciag.ufu.br. Autor para correspondência.

${ }^{2}$ Universidade Estadual de Goiás, Anápolis, GO, Brasil. E-mail: fialhoreis@ibest.com.br.

${ }^{3}$ Universidade Estadual de Goiás, Anápolis, GO, Brasil. E-mail: robertogpi@yahoo.com.br. 
fungicidas com características de ação sistêmica (ANTUNIASSI et al., 2004).

Uma das formas de se obter boa deposição da pulverização sob alvos biológicos é a seleção correta das pontas de pulverização (SCUDELER et al., 2004). Essas pontas são os componentes mais significativos dos pulverizadores e apresentam como funções básicas: fragmentar o líquido em pequenas gotas, distribuir as gotas e controlar a saída do líquido por unidade de área (SIDAHMED, 1998).

Para a aplicação de fungicidas na soja, pontas muito utilizadas são aquelas que produzem gotas finas, como as de jato plano padrão. No entanto, em virtude do seu espectro de gotas propiciar a deriva, tem-se tentado utilizar pontas que produzem gotas maiores, como as de jato plano de pré-orifício, de jato plano de indução de ar e de jato plano duplo de indução de ar. Essas, no entanto, podem comprometer a cobertura das plantas, em razão de as gotas serem de maior tamanho. Conseqüentemente, poderá haver menor controle de doenças. De forma geral, gotas pequenas são facilmente transportadas pelo vento, porém propiciam maior cobertura do alvo, condição desejada sobretudo quando da utilização de fungicidas protetores.

Outra variável importante na aplicação é o volume de calda. Prática comum era se aplicar volumes superiores a 200L ha-1; atualmente, entretanto, existe tendência a se reduzir o volume de calda, visando a diminuir os custos de aplicação e aumentar a eficiência da pulverização (SILVA, 1999). O uso de menor volume aumenta a autonomia e a capacidade operacional dos pulverizadores.

A redução do volume de calda requer, porém, um aprimoramento da tecnologia de aplicação empregada no campo. Segundo SALYANI (1999), a redução do orifício de saída das pontas, para obter menor volume de aplicação, aumenta o risco de deriva em virtude da diminuição do tamanho das gotas geradas. Em geral, gotas menores são mais eficazes no combate a pragas e doenças, porém pouco seguras, sob o ponto de vista ambiental. Assim, há a necessidade de estudos que viabilizem e otimizem a redução de volume de pulverização nas aplicações de fungicidas, permitindo a utilização de pontas e volumes de calda adequados para uma boa cobertura, sem a ocorrência de deriva (SILVA, 1999).

Os resultados das pulverizações nas lavouras são variáveis. O grau de sucesso geralmente é determinado pela quantidade e uniformidade da cobertura. A eficácia do tratamento depende não somente da quantidade de material depositado sobre a vegetação, mas também da uniformidade de cobertura do alvo. De maneira geral, a deposição é menor nas partes mais baixas e internas do dossel das culturas. No caso de fungicidas, esta desuniformidade proporciona baixa eficácia no controle de doenças, principalmente no caso de fungicidas que requerem cobertura uniforme de toda a planta. Esse problema se acentua nas aplicações em que se utilizam pontas de jato plano que, em geral, produzem menor número de gotas por área e menor turbulência do que as pontas de jato cônico vazio.

Desta forma, torna-se importante verificar se a utilização de menores volumes de calda, associada ao emprego de pontas de pulverização com classe de tamanho de gotas variando de média a grossa, pode comprometer a eficiência da aplicação de fungicida na soja. O presente trabalho teve como objetivo avaliar o controle químico do patógeno associado à ferrugem asiática e a deposição da calda fungicida aplicada na cultura da soja, em função de diferentes volumes de aplicação e tipos de ponta de pulverização.

\section{MATERIAL E MÉTODOS}

O experimento foi conduzido em área experimental da Agência Rural do Estado de Goiás, localizada no município de Anápolis, GO. A área apresenta Latossolo Vermelho-Escuro Eutrófico, com textura argilosa. Realizou-se a semeadura direta da cultivar de soja “Emgopa 313” (ciclo tardio) no dia 6/ 12/2004, utilizando-se 15 sementes por metro e espaçamento entre fileiras de $50 \mathrm{~cm}$. Essa cultivar é de grande utilização nos Estados de Goiás e Mato Grosso; no entanto é susceptível à ferrugem asiática. Doze dias antes da semeadura, foi realizada dessecação de Brachiaria decumbens presente na área utilizando os herbicidas glyphosate e 2, 4-D.

O ensaio foi conduzido no delineamento em blocos ao acaso, com quatro repetições, em esquema bifatorial $(4 \times 2)+1$ : quatro tipos de ponta de pulverização (jato plano padrão, jato plano de préorifício, jato plano de indução de ar e jato plano duplo de indução de ar), dois volumes de aplicação (115 e $160 \mathrm{~L} \mathrm{ha}^{-1}$ ) e um tratamento adicional que não recebeu fungicida (testemunha).

Utilizou-se o fungicida sistêmico do grupo triazol tebuconazole (formulação concentrado emulsionável), na dose recomenda pelo fabricante (100g $\mathrm{ha}^{-1}$ de ingrediente ativo). A aplicação foi realizada utilizando-se um pulverizador costal manual dotado de uma barra com disposição simultânea de dois bicos espaçados $50 \mathrm{~cm}$ um do outro. Visando à manutenção da pressão constante ao longo da aplicação, instalouse no pulverizador uma válvula reguladora de pressão. 
Em todas as aplicações, empregou-se a pressão de $200 \mathrm{kPa}$ e velocidade de avanço de $5 \mathrm{~km} \mathrm{~h}^{-1}$ (controlada por um passômetro). A altura de aplicação em relação à cultura foi de $50 \mathrm{~cm}$.

Utilizaram-se pontas de pulverização hidráulicas, fabricadas em cerâmica, com ângulo de pulverização de $110^{\circ}$ (Tabela 1 ). A vazão das pontas foi selecionada de forma a se obter os volumes de aplicação testados: 115 e 160L ha-1. Para isso, empregaram-se pontas 110-015 e 110-02. As pontas de jato plano padrão são de uso geral, produzindo gotas menores em relação às pontas de pré-orifício e de indução de ar. As pontas de jato plano de pré-orifício apresentam um orifício antes da abertura para a formação do jato, que permite a formação de gotas de maior diâmetro. As pontas de indução de ar possuem um sistema venturi que faz com que as gotas se tornem mais grossas, com bolhas de ar em seu interior. As pontas de jato plano duplo apresentam dois orifícios para a saída de jatos planos com ângulo de $60^{\circ}$ entre eles.

O fungicida tebuconazole foi aplicado com a soja em estágio $R_{2}$. O manejo fitossanitário utilizado foi o preconizado para a cultura. A avaliação da eficácia do fungicida no controle da ferrugem da soja foi realizada mediante a comparação da severidade da doença e da produtividade da soja entre parcelas tratadas com fungicida e parcelas não-tratadas (testemunha).

Também foi analisada a deposição da calda fungicida pulverizada sobre as plantas de soja por meio da quantificação de um traçador, adicionado à calda, nas folhas, em duas posições na planta, conforme metodologia apresentada por PALLADINI (2000). Empregou-se como traçador, um composto do corante alimentício azul brilhante (Corante Azul FCF, Duas Rodas Industrial), catalogado internacionalmente pela "Food, Drug \& Cosmetic" como FD\&C Blue n.1, na concentração de $1.560 \mathrm{mg} \mathrm{L}^{-1}$ para volumes de aplicação de $115 \mathrm{~L} \mathrm{ha}^{-1}$, e de $1.290 \mathrm{mg} \mathrm{L}^{-1}$ para volumes de aplicação de 160L ha-1. Este foi detectado por absorbância em espectrofotometria.

Após a aplicação em cada parcela, foram marcadas dez plantas ao acaso. Em cada planta foram coletados dois folíolos centrais, um na parte superior e outro na parte inferior da planta, que foram, então, colocados em recipientes plásticos separados, adicionando-lhes 100mL de água destilada. Esses recipientes foram fechados, agitados por 30s e conservados ao abrigo da luz. Posteriormente, fez-se a quantificação da coloração por absorbância em 630nm, conforme metodologia descrita por PALLADINI (2000). Os folíolos tiveram sua área medida por meio de digitalização e análise no programa computacional "Image Tool” versão 3.0.

Com o uso da curva de calibração, obtida por meio de soluções-padrão, os dados de absorbância foram transformados em concentração $\left(\mathrm{mg} \mathrm{L}^{-1}\right)$ e, de posse da concentração inicial da calda e do volume de diluição das amostras, determinou-se o volume retido no alvo. Procedeu-se, então, a divisão do depósito total pela área foliar de remoção, obtendo-se, assim, a quantidade em $\mu \mathrm{L} \mathrm{cm}^{-2}$ de folha.

A avaliação da severidade da ferrugem foi realizada a partir do aparecimento dos primeiros sintomas e, depois, a intervalos de aproximadamente dez dias, totalizando cinco avaliações. A primeira avaliação da severidade foi feita aos 75 dias após a emergência (DAE). Para tal, utilizou-se a escala diagramática proposta por CANTERI \& GODOY (2003). Na avaliação, em cada parcela, marcaram-se dez plantas, escolhidas ao acaso, e, em cada planta, três folhas: uma na parte inferior, outra na parte intermediária e a terceira na parte superior do dossel. As médias dessas avaliações constituíram a severidade média da doença.

Com os dados da severidade da doença, procedeu-se a construção da curva de progresso e a determinação da área abaixo da curva de progresso da doença (AACPD). Esta foi calculada pelo somatório

Tabela 1 - Tipos de pontas utilizadas no experimento. Anápolis, GO, 2005.

\begin{tabular}{llll}
\hline Ponta & \multicolumn{1}{c}{ Descrição } & Fabricante & Espectro de gotas* \\
\hline AD-IA 110-015 & Jato plano de indução de ar & Magno & Muito grossas \\
AD-IA 110-02 & Jato plano de indução de ar & Magno & Muito grossas \\
AD-IA/D 110-015 & Jato plano duplo de indução de ar & Magno & Muito grossas \\
AD-IA/D 110-02 & Jato plano duplo de indução de ar & Magno & Muito grossas \\
ADI 110-015 & Jato plano de pré-orifício & Albuz & Médias \\
ADI 110-02 & Jato plano de pré-orifício & Albuz & Médias \\
API 110-015 & Jato plano padrão & Albuz & Finas \\
API 110-02 & Jato plano padrão & Albuz & Finas \\
\hline
\end{tabular}

*Indicado pelo fabricante. 
das áreas trapezoidais (CAMPBELL \& MADDEN, 1990).

A colheita foi realizada aos $130 \mathrm{DAE}$, sendo avaliada a produtividade nas parcelas experimentais, de $15 \mathrm{~m}^{2}$ ( 5 x 3m), constituídas de seis fileiras de cinco metros de comprimento. A umidade dos grãos foi corrigida para $13 \%$.

Durante as aplicações do fungicida, monitoraram-se as condições climáticas: temperatura inferior a $28^{\circ} \mathrm{C}$, umidade relativa do ar superior a $60 \%$ e velocidade do vento entre 1 e $3 \mathrm{~m} \mathrm{~s}^{-1}$. Os dados de deposição foram submetidos à análise de variância e as médias comparadas pelo teste Tukey a $5 \%$ de probabilidade de erro. Os dados de severidade da ferrugem e de produtividade da soja também foram submetidos à analise de variância. Quando o teste F da análise de variância indicou significância, ao nível de 5\% de probabilidade de erro, as médias dos tratamentos com aplicação de fungicida foram comparadas com a testemunha, utilizando-se o teste de Dunnett, também a $5 \%$ de probabilidade de erro.

\section{RESULTADOS E DISCUSSÃO}

Na tabela 2, apresentam-se as médias dos volumes de calda retido nas partes superior e inferior do dossel. Não houve interação entre pontas e volumes de calda, indicando a independência entre os dois fatores. Na posição superior, não houve diferença significativa entre as médias do volume de calda retido na folhagem com as diferentes pontas, mostrando não haver diferenças entre elas quanto à deposição. De forma semelhante, SCUDELER et al. (2004), avaliando a deposição promovida por gotas finas e por gotas muito grossas, pulverizadas por diferentes pontas, também não encontraram diferença na parte superior do dossel. Já na parte inferior das plantas, a ponta de jato plano padrão promoveu maior cobertura das folhas. Provavelmente, isso ocorreu em virtude de suas gotas serem de menor tamanho em relação às outras pontas. É esperado que, em geral, pontas que produzem gotas de menor tamanho promovam maior cobertura do alvo, principalmente na ausência de vento. Esse resultado concorda com os dados apresentados por ANTUNIASSI et al. (2004). Os autores, avaliando a cobertura de folhas de soja com diferentes pontas de pulverização, concluíram que as gotas finas propiciam melhores coberturas nas posições média e baixa das plantas.

O volume de aplicação de 160L ha-1 proporcionou maior retenção de calda nas posições superior e inferior do dossel, quando comparado ao volume de $115 \mathrm{~L} \mathrm{ha}^{-1}$. Esse resultado indica maior distribuição de calda no alvo empregando-se maior volume de aplicação, condição desejada principalmente quando do uso de fungicidas protetores. Em geral, espera-se que o incremento do volume de aplicação propicie aumento do volume de calda retido até certo ponto, a partir do qual a superfície não mais retém o líquido, passando a ocorrer o escorrimento, o que não é desejável. CROSS \& BERRIE (1993) avaliaram, em túnel de vento, a influência do volume de aplicação (50, 100 e 200 $\left.\mathrm{L} \mathrm{ha}^{-1}\right)$ na deposição da calda pulverizada e também encontraram maior cobertura do alvo empregando maiores volumes de aplicação.

A diferença de volume retido entre as posições superior e inferior do dossel em relação ao volume retido na posição superior (Tabela 3) dá indicação da uniformidade de deposição. Essa não foi homogênea, pois houve diferença de retenção ao longo do dossel das plantas. As pontas de jato plano padrão apresentaram a maior uniformidade de distribuição.

Tabela 2 - Volume de calda de pulverização retido na folhagem da soja $\left(\mu \mathrm{L} \mathrm{cm}{ }^{-2}\right.$ de folha) nas posições superior e inferior do dossel. Anápolis, GO, 2005.

\begin{tabular}{|c|c|c|c|c|c|c|}
\hline \multirow{3}{*}{ Pontas de pulverização } & \multicolumn{3}{|c|}{ Posição superior } & \multicolumn{3}{|c|}{ Posição inferior } \\
\hline & \multicolumn{2}{|c|}{ Volume de calda $\left(\mathrm{L} \mathrm{ha}^{-1}\right)$} & \multirow{2}{*}{ Média } & \multicolumn{2}{|c|}{ Volume de calda ( $\left.\mathrm{L} \mathrm{ha}^{-1}\right)$} & \multirow{2}{*}{ Média } \\
\hline & 160 & 115 & & 160 & 115 & \\
\hline Jato plano padrão & 0,454 & 0,357 & $0,406^{\text {ns }}$ & 0,408 & 0,306 & $0,357 a^{*}$ \\
\hline Jato plano de pré-orifício & 0,565 & 0,492 & 0,529 & 0,239 & 0,205 & $0,222 b$ \\
\hline Jato plano duplo de indução de ar & 0,580 & 0,408 & 0,494 & 0,225 & 0,140 & $0,183 b$ \\
\hline Jato plano de indução de ar & 0,471 & 0,449 & 0,460 & 0,261 & 0,067 & $0,164 b$ \\
\hline Média & $0,517 \mathrm{~A}$ & $0,427 \mathrm{~B}$ & & $0,283 \mathrm{~A}$ & $0,180 \mathrm{~B}$ & \\
\hline
\end{tabular}

*Médias seguidas por letras distintas maiúsculas nas linhas e por minúsculas nas colunas diferem significativamente, ao nível de 5\% de probabilidade de erro pelos testes F e de Tukey, respectivamente.

${ }^{\text {ns }}$ Teste F não significativo ao nível de 5\% de probabilidade de erro. 
Tabela 3 - Diferença percentual de volume de calda retido entre as posições superior e inferior do dossel da cultura da soja em relação ao volume retido na posição superior, após a aplicação do fungicida. Anápolis, GO, 2005.

\begin{tabular}{|c|c|c|c|}
\hline \multirow{2}{*}{ Pontas de pulverização } & \multicolumn{2}{|c|}{ Volume de calda } & \multirow{2}{*}{ Média* } \\
\hline & $160 \mathrm{~L} \mathrm{ha}^{-1}$ & $115 \mathrm{~L} \mathrm{ha}^{-1}$ & \\
\hline Jato plano padrão & 10,1 & 14,3 & $12,2 b$ \\
\hline Jato plano de pré-orifício & 57,7 & 58,3 & $58,0 \mathrm{a}$ \\
\hline Jato plano duplo de indução de ar & 61,2 & 65,7 & $63,4 a$ \\
\hline Jato plano de indução de ar & 44,6 & 85,1 & $64,8 \mathrm{a}$ \\
\hline Média & $43,4 \mathrm{~B}$ & $55,8 \mathrm{~A}$ & \\
\hline
\end{tabular}

*Médias seguidas por letras distintas maiúsculas nas linhas e por minúsculas nas colunas diferem significativamente entre si, ao nível de 5\% de probabilidade de erro, pelo testes F e de Tukey, respectivamente.

Como sua deposição de calda na parte inferior foi maior, ela refletiu na uniformidade de cobertura do dossel como um todo. Isso provavelmente também ocorreu em virtude de suas gotas serem menores em relação às outras pontas de pulverização.

Não ocorreram condições propícias à deriva durante as aplicações do fungicida, o que auxiliou o resultado obtido. Possivelmente, em condições de vento forte, as gotas pequenas produzidas pela ponta de jato plano padrão seriam arrastadas, dificultando uma boa deposição no dossel.

Os volumes de aplicação proporcionaram diferença na quantidade de calda retida entre as posições do dossel. O volume de 115L ha-1 proporcionou maior diferença de volume retido entre as posições superior e inferior, indicando menor uniformidade de deposição de calda na planta.

Em trabalho realizado por DERKSEN \& SANDERSON (1996), avaliando a influência do volume de calda na deposição foliar de agrotóxicos, verificouse melhor cobertura e menores variações de deposição ao longo do dossel com o uso de altos volumes de aplicação. Os autores explicaram que maiores volumes permitem uma redistribuição de produto por meio do escorrimento da parte superior para a parte inferior, o que causa maior deposição nas partes inferiores e, com isso, maior uniformidade de deposição. No entanto, essas aplicações apresentam maiores riscos de contaminação do solo, em virtude da possibilidade da não-retenção de produto nas folhas.

A ferrugem da soja apresentou os primeiros sintomas cerca de 70 DAE. Nas parcelas tratadas, as plantas apresentaram comportamento similar e não ocorreu avanço acentuado da doença ao longo do ciclo, contrastando com a testemunha, o que demonstra a ação do fungicida tebuconazole no controle da doença.

O efeito das pontas e dos volumes de pulverização na área abaixo da curva de progresso (AACP) da ferrugem e na produtividade da soja é mostrado na tabela 4. Nota-se, pela análise de variância, que não houve diferença entre pontas e entre volumes de calda pulverizada. Houve diferença apenas entre as parcelas tratadas e a testemunha (Tabela 5). Todos os tratamentos que receberam o fungicida tebuconazole superaram a testemunha, indicando que o controle da doença foi realizado de forma eficiente pelo produto.

Tabela 4 - Resumo da análise de variância da produtividade da soja e dos dados de área abaixo da curva de progresso (AACP) da ferrugem, em função da aplicação de fungicida com diferentes pontas e volumes de calda. Anápolis, GO, 2005.

\begin{tabular}{lllc}
\hline & & & \\
Fontes de Variação & GL & AACP da ferrugem & Productividade da soja \\
\cline { 3 - 4 } & & Não significativo & Não significativo \\
Pontas de pulverização & 3 & Não significativo & Não significativo \\
Volumes de calda & 1 & Não significativo & Não significativo \\
Volumes x Pontas & 1 & Significativo & Significativo \\
Fatorial x Testemunha & 1 & 16,5 & 13,8 \\
CV $(\%)$ & & & \\
\hline
\end{tabular}

*Significância pelo teste $\mathrm{F}$, ao nível de $5 \%$ de probabilidade de erro.

Ciência Rural, v.36, n.5, set-out, 2006. 
Tabela 5 - Efeito do tipo de ponta de pulverização e do volume de calda utilizados na aplicação de fungicida, na área abaixo da curva de progresso (AACP) da ferrugem e na produtividade da soja. Anápolis, GO, 2005.

\begin{tabular}{lccc}
\hline Ponta de pulverização & Volume de calda $\left(\mathrm{L} \mathrm{ha}^{-1}\right)$ & AACP da ferrugem & Produtividade $\left(\mathrm{kg}\right.$ ha $\left.{ }^{-1}\right)$ \\
\hline Jato plano de indução de ar & 115 & $14,3^{*}$ & $14,1^{*}$ \\
Jato plano duplo de indução de ar & 115 & $18,7^{*}$ & $2.576^{*}$ \\
Jato plano de pré-orifício & 115 & $15,8^{*}$ & $2.391^{*}$ \\
Jato plano padrão & 115 & $19,3^{*}$ & $2.135^{*}$ \\
Jato plano de indução de ar & 160 & $16,2^{*}$ & $2.120^{*}$ \\
Jato plano duplo de indução de ar & 160 & $15,9^{*}$ & $2.484^{*}$ \\
Jato plano de pré-orifício & 160 & $17,2^{*}$ & $2.413^{*}$ \\
Jato plano padrão & 160 & 124,8 & $2.247^{*}$ \\
Testemunha & & & 1.682 \\
\hline
\end{tabular}

*As médias seguidas por um asterisco diferem significativamente da testemunha, ao nível de 5\% de probabilidade de erro, pelo teste de Dunnett.

A aplicação do fungicida promoveu um aumento médio de produtividade da soja de $41 \%$ em relação à testemunha, evidenciando que o controle da ferrugem foi viável, independentemente do tipo de ponta de pulverização ou do volume de calda aplicado, concordando com BOLLER et al. (2002). Os autores obtiveram resultados semelhantes de produtividade da soja aplicando fungicida sistêmico para o controle de oídio (Microsphaera diffusa Cooke \& Peck), com diferentes pontas de pulverização, indicando preferência para aquelas pontas com menor risco de deriva. Em trabalho realizado por CUNHA et al. (2005), também não houve influência do tipo de ponta de pulverização (jato plano padrão, jato plano antideriva e jato cônico vazio) utilizada na aplicação de fungicida, no controle de doenças do feijoeiro.

A inexistência de diferença significativa no rendimento dos grãos entre as parcelas tratadas com o fungicida pode ser atribuída ao fato de que, mesmo sendo significativas as diferenças entre a deposição da calda fungicida proporcionada pelas diferentes pontas e pelos volumes de aplicação, elas foram insuficientes para afetar a produtividade das plantas. $\mathrm{O}$ fato de o fungicida ser sistêmico também pode ter influenciado os resultados encontrados.

\section{CONCLUSÕES}

O volume de calda de $160 \mathrm{~L} \mathrm{ha}^{-1}$ e a utilização da ponta de pulverização de jato plano padrão proporcionaram maior uniformidade na distribuição da calda fungicida sobre as plantas de soja. A produtividade de grãos nas parcelas tratadas foi em média $41 \%$ superior à obtida na testemunha, sem a aplicação do fungicida, independentemente das pontas de pulverização (jato plano padrão, jato plano de préorifício, jato plano de indução de ar e jato plano duplo de indução de ar) ou dos volumes de calda (115 e $160 \mathrm{~L}$ $\mathrm{ha}^{-1}$ ) empregados na aplicação do fungicida tebuconazole.

\section{AGRADECIMENTO}

Ao Prof. Fernando César Juliatti, pela revisão técnica do manuscrito.

\section{REFERÊNCIAS}

ANTUNIASSI, U.R. et al. Avaliação da cobertura de folhas de soja em aplicações terrestres com diferentes tipos de pontas. In: SIMPÓSIO INTERNACIONAL DE TECNOLOGIA DE APLICAÇÃO DE AGROTÓXICOS, 3., 2004, Botucatu, SP. Anais... Botucatu: FEPAF, 2004. p.48-51.

BOLLER, W. et al. Efeitos da utilização de diferentes pontas de pulverização no controle químico de oídio em soja. In: REUNIÃO DE PESQUISA DE SOJA DA REGIÃO SUL, 30., 2002, Cruz Alta, RS. Anais... Cruz Alta: Fundacep-Fecotrigo, 2002. p.104.

CAMPBELL, C.L.; MADDEN, L.V. Introduction to plant disease epidemiology. New York: John Wiley \& Sons, 1990. 532p.

CANTERI, M.G.; GODOY, C.V. Escala diagramática para avaliação da severidade da ferrugem da soja. Summa Phytopathologica, Botucatu, v.29, p.89, 2003.

CROSS, J.V.; BERRIE, A.M. Spray deposits and efficacy of a tunnel sprayer at three volume rates $(50,100,200$ l/ha) in comparison with an axial fan sprayer (50 l/ha) on apple. In: INTERNATIONAL SYMPOSIUM ON PESTICIDE APPLICATION TECHNIQUES, 2., 1993, Strasbourg. Proceedings... Strasbourg: BCPC, 1993. p.273-280.

CUNHA, J.P.A.R. et al. Avaliação de pontas de pulverização hidráulicas na aplicação de fungicida em feijoeiro. Ciência Rural, Santa Maria, v.35, n.5, 1069-1074, 2005.

DERKSEN, R.C.; SANDERSON, J.P. Volume, speed and distribution technique effects on poinsettia foliar deposit. Transactions of the ASAE, St. Joseph, v.39, n.1, p.5-9, 1996. 
PALLADINI, L.A. Metodologia para avaliação da deposição em pulverizações. 2000. 111f. Tese (Doutorado em Agronomia) - Universidade Estadual Paulista, Botucatu, SP.

SALYANI, M. Optimization of sprayer output at different volume rates. St. Joseph: ASAE, 1999. CD ROM. (ASAE Paper n.99-1028).

SCUDELER, F. et al. Ângulo da barra e ponta de pulverização na deposição da pulverização em soja. In: SIMPÓSIO INTERNACIONAL DE TECNOLOGIA DE APLICAÇÃO DE
AGROTÓXICOS, 3., 2004, Botucatu, SP. Anais... Botucatu: FEPAF, 2004. p.13-16.

SIDAHMED, M.M. Analytical comparison of force and energy balance methods for characterizing sprays from hydraulic nozzles. Transactions of the ASAE, St. Joseph, v.41, n.3, p.531-536, 1998.

SILVA, O.C. Tecnologia de aplicação de fungicidas. In: CANTERI, M.G. et al. Principais doenças fúngicas do feijoeiro. Ponta Grossa: UEPG, 1999. p.127-137. 